\title{
Development of a Health Risk Communication Tool to address Oral Health Issues of Schoolchildren of Balotra Block, Rajasthan
}

\author{
'Zakariya Chauhan, ${ }^{2}$ Navya Vyas, ${ }^{3}$ Shashidhar Acharya, ${ }^{4}$ Nitin K Joshi, ${ }^{5}$ Sneha Maheshwari
}

\begin{abstract}
Aim: Oral health is one of the leading preventable problems around the globe. India is the second largest populous country, with the majority of the population living in rural areas. Rural population still uses traditional methods to maintain oral hygiene as opposed to urban population which has progressed to electronic toothbrushes. The aim of the present study was to identify the predisposing risk factors for oral health issues among early adolescents and develop a health risk communication tool that will aid in addressing the problem of oral hygiene in school-going children.
\end{abstract}

Materials and methods: A cross-sectional study that included 920 school-going children of class 6 to 9th was conducted in the region of Balotra, Rajasthan, India. Single-stage cluster sampling technique was used in the study to select and collect data from children from 23 (15 government and 8 private) schools that were randomly selected. Analysis was done using Statistical Package for the Social Sciences (SPSS) version 15.0.

Results: Overall, the prevalence of caries and dental fluorosis was found to be $47 \%$ and $61 \%$ respectively. The oral health problem of dental caries was seen to be less prevalent in girls (39.7\%). Dental caries were found to be more in government schools (58.7\%) and in rural areas (59.6\%) as compared with urban areas $(52.1 \%)$. It was also observed that prevalence of dental caries was more in permanent dentition (44\%) as compared with primary dentition (14\%). Factors found to be associated with caries were private schools, age of the children, and irregular brushing habits.

Conclusion: Based on the prevalence of caries and fluorosis and other findings of the study, it can be concluded that children lack knowledge and awareness about oral hygiene. There is a need to enhance the oral health knowledge level of schoolgoing children. Implementation of a school health program would help change the status quo, and positively influence oral health and well-being of children.

\footnotetext{
1,2Prasanna School of Public Health, Manipal Academy of Higher Education, Manipal, Karnataka, India

${ }^{3}$ Department of Public Health Dentistry, Manipal College of Dental Sciences, Manipal Academy of Higher Education Manipal, Karnataka, India

${ }^{4}$ Department of Public Health, Jodhpur School of Public Health Jodhpur, Rajasthan, India

${ }^{5}$ Private Dental Practitioner, Jodhpur, Rajasthan, India

Corresponding Author: Navya Vyas, Prasanna School of Public Health, Manipal Academy of Higher Education, Manipal, Karnataka India, Phone: +919538126121, e-mail: navya.vyas@manipal.edu
}

Clinical significance: Initiatives should be taken in the field of public health dentistry to address the problems of caries and dental fluorosis as they are quite prevalent in the area.

Keywords: Health risk communication tool, Oral health, Schoolchildren.

How to cite this article: Chauhan Z, Vyas N, Acharya S, Joshi NK, Maheshwari S. Development of a Health Risk Communication Tool to address Oral Health Issues of Schoolchildren of Balotra Block, Rajasthan. World J Dent 2017;8(6):461-466.

\section{Source of support: Nil}

Conflict of interest: None

\section{INTRODUCTION}

India is a vast country, with diversity in demography, socioeconomic strata, religious and cultural beliefs and practices, lifestyle choices, and preferences. India is the second most populous country and has many challenges, especially in the public health sector. Based on where they live, the rural population still uses traditional methods to maintain oral hygiene (such as neem sticks and mud) as opposed to the urban populations that have progressed to electronic toothbrushes. Even though a program document exists for oral health, the oral health needs of the people are not adequately met.

Oral health problems are preventable; still, dental caries is one of the leading health problems around the globe. Oral health problems can be as small as tobacco stains on teeth, to as large as cancers of the neck. The World Dental Federation estimates that $83 \%$ of children aged 6 to 19 years have dental caries. ${ }^{1}$ Dental treatment is one of the most expensive treatments in the world. ${ }^{2}$ In general, every country develops its own health policy, which is aimed at defined goals. The Government of India had put a step forward to enhance the health care system by introducing the National Health Policy (1983), which was reformed to lay down a new policy structure for the speedy achievement of the public health goals in 2002 and recently in 2017. ${ }^{3}$ Since the National Oral Health Program in India is in its nascent stages, and not appropriately implemented, most of the people visit private dental clinics and hospitals for treatment. Dental treatment is not covered by insurance in India. ${ }^{4}$ This increases outof-pocket expenditure for the people. 
Recent studies have suggested that $50 \%$ of the schoolgoing children have been suffering from dental caries and more than $9 \%$ of the population are affected by periodontal disease. ${ }^{5}$ There is a huge demand for financial resources and time to treat dental caries only in schoolchildren of the country. Surveys have found the prevalence of dental caries in children aged 5 years to be $50 \% ; 52.5 \%$ in 12 -yearolds; $61.4 \%$ in 15 -year-olds; $79.2 \%$ in 35 to 44 -year-olds; and $84.7 \%$ in 65 to 74 -year-olds. ${ }^{6}$ However, with a significant geographic imbalance among dental colleges, there has been a great variation in the dentist-to-population ratio in rural and urban areas. There was a marked improvement between the 1980s and 1990s, from 1:80,000 to 1:42,500. At present, the dentist-to-population ratio in India is 1:30,000. ${ }^{7}$

The irony of the budget allocation in India is that, out of the total budget, the amount that is dedicated to health expenditure is very meager, and out of this amount, only a minute percentage is allocated for oral health-related activities. ${ }^{7}$ Oral diseases affect the quality-of-life of children and account for pain, impaired esthetics, recurrent infections, eating troubles, sleeping difficulties, emergency visits to dentists and hospitals, poor ability to learn, insufficient nutrition, and improper growth and development. ${ }^{8}$ Dental caries affect the children socially as well as psychologically. Furthermore, treating dental caries in children is expensive not only due to the direct costs of treatment, but also due to the indirect costs, such as the time taken off by the parents to take the child to a dentist. ${ }^{9}$

Rajasthan is the seventh populous state of India, where the majority of the population lives in rural areas. Population ratio of the urban areas is $24.87 \%$, whereas rural population is $75.13 \%$, with a literacy rate of $66 \%$ as per the Rajasthan population census data, $2011 .{ }^{10}$ The target group in the present study was the children studying in class 6th to class 9th in Balotra block of Barmer district. This district is located in the western part of Rajasthan. The dentists in this region are mostly to be found in distant urban areas with more than 20 dentists in the urban regions of Balotra.

It has been observed that due to lack of health-education program and less awareness regarding oral health, people face a lot of oral health-related troubles. Furthermore, betel nut and tobacco consumption are one of the major issues in this region. Both males and females have the habit to smoke and chew smokeless tobacco very frequently. The school-going children also have habits of betel nuts chewing, which exposes them to detrimental oral health. ${ }^{11}$

\section{AIMS AND OBJECTIVES}

The aim of the present study was to identify the predisposing risk factors for oral health issues among early adolescents in this region of Rajasthan and also to determine the prevalence of oral health problems among early adolescents in school; and to also develop a health risk communication tool, which will aid in addressing the problem of oral hygiene in school-going children.

\section{MATERIALS AND METHODS}

The present study was cross-sectional in nature. The study was conducted from January 2017 to May 2017. Schoolchildren of 6th to 9th class, who were willing to participate, and children, who were present on the day of the study, were included in the study. The study constituted of four components which are as follows:

1. Oral health screening

2. Questionnaire survey

3. Data analysis

4. Preparation of health risk communication tool.

\section{Sampling Technique}

A permission letter was taken from the Block Education Department of Balotra block before the onset of the study. Ethical clearance was obtained from the ethical committee of the organization. Single-stage cluster sampling technique was used for the study with each school being a cluster. Totally, 23 schools were randomly selected until the sample size was achieved. The selection included 15 government schools and 8 private schools. The study was conducted with a sample size of 920 students, with 40 students selected from each school.

Before the onset of the study, all the selected schools' principals were informed. Two days before the study, an assent form and participation information sheet were given to the children through the teachers. The "World Health Organization (WHO) oral health questionnaire for children" was used for data collection.

Data collection was done from January 2017 to March 2017. The children were initially screened for oral hygiene and then interviewed using a structured questionnaire. Data was analyzed using SPSS version 15.0. Descriptive statistics were computed and reported. Cross-tabs and custom tables were used for stratification of data according to sociodemographic factors. Prevalences of dental caries and dental fluorosis were calculated from the data.

Associations were tested at $95 \%$ confidence interval, with alpha set at $5 \%$. Cutoff for $\mathrm{p}$-value was set at 0.05 for hypothesis testing. Logistic regression was done to find the factors associated with dental caries and dental fluorosis separately.

\section{Health Risk Communication Tool}

After obtaining the results from the data, a health risk communication tool was developed (Fig. 1). This tool was 


\section{GOOD ORAL HYGIENE PRACTICES}

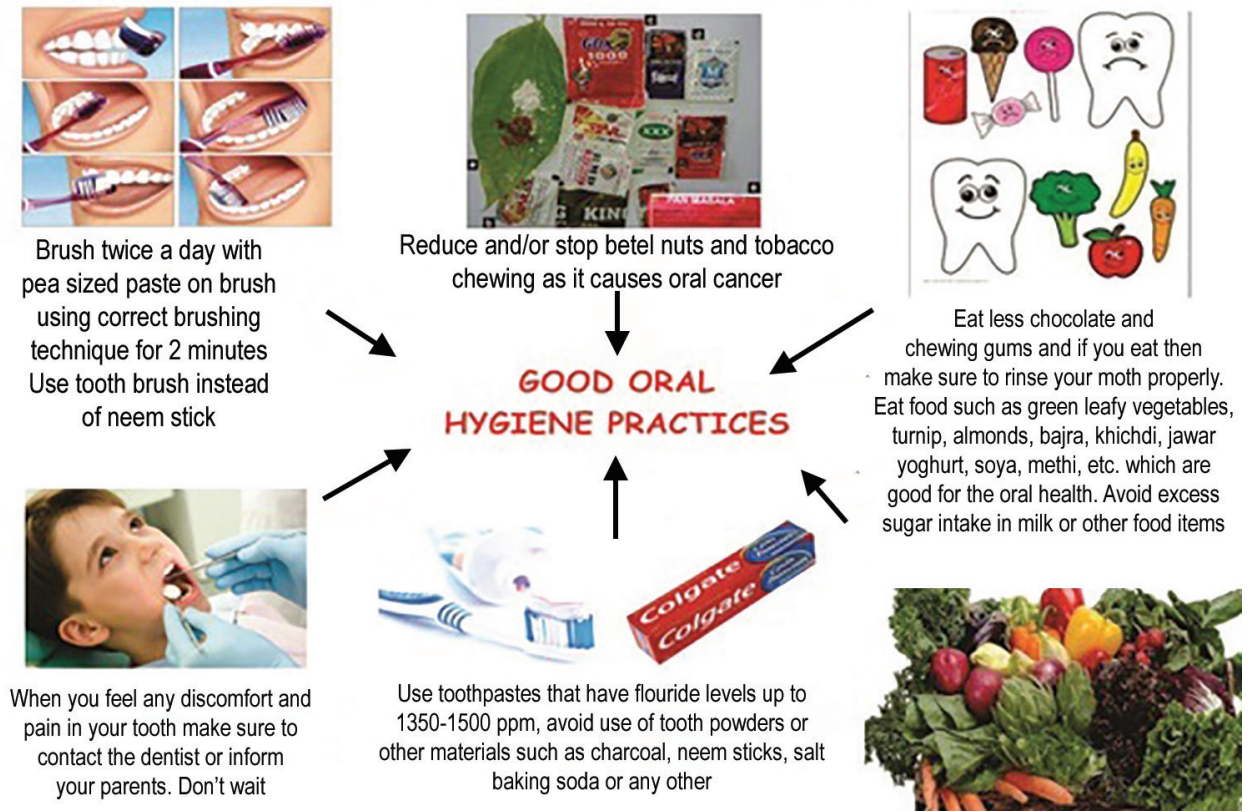

Fig. 1: Oral health risk communication tool

used as a means of health education in all the schools visited.

This tool included the following instructions (along with pictorial representation of each):

- Brush your teeth with proper brushing technique using toothbrush for 2 minutes daily.

- Brush twice a day, in the morning and before going to bed.

- Do not use charcoal and neem stick for brushing teeth.

- Eat more leafy vegetables and always brush teeth after eating chocolates and candies.

- Say no to betel nuts, cigarette, and tobacco chewing.

- Inform your parents and visit a dentist if you feel any pain and discomfort in your teeth.

This tool was prepared and shown to subject experts for feedback and improvement. Based on the input, the

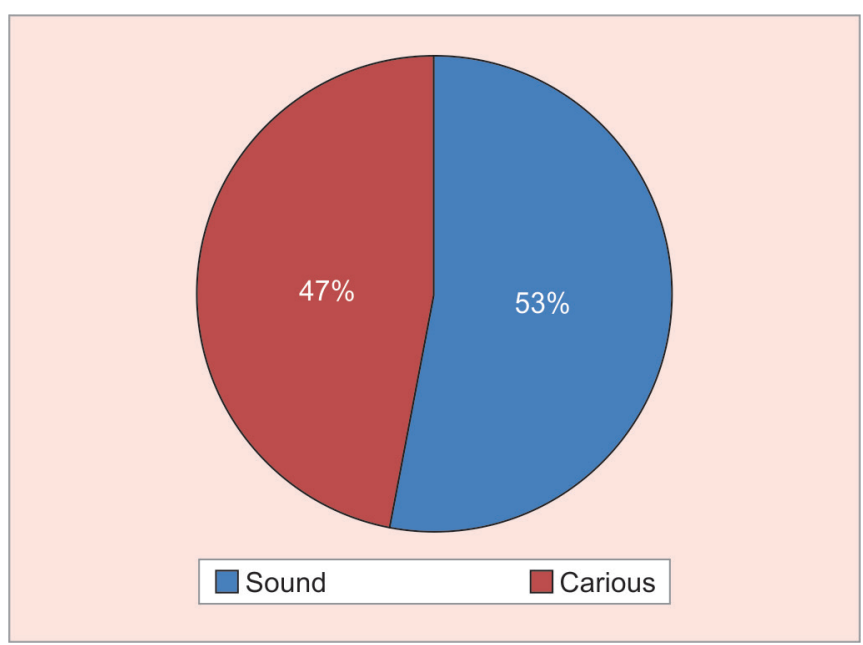

Graph 1: Distribution of caries among the study population $(n=920)$ final tool was designed, printed, and put up in all the schools visited.

\section{RESULTS}

The overall prevalence of dental caries was $47 \%$ since the primary dentition was lost by 12 years of age and replaced entirely by permanent dentition. The prevalence of caries in permanent dentition was taken as the finding of interest and used to represent the prevalence of dental caries as a whole (Graph 1). Prevalence of dental fluorosis observed during the study in the Balotra block, which is a fluoride-endemic zone, was $61 \%$ (Graph 2).

Levels of education of both parents were recorded in the study. While one-fourth of the mothers had no formal education, only $4 \%$ of the fathers did not attend formal

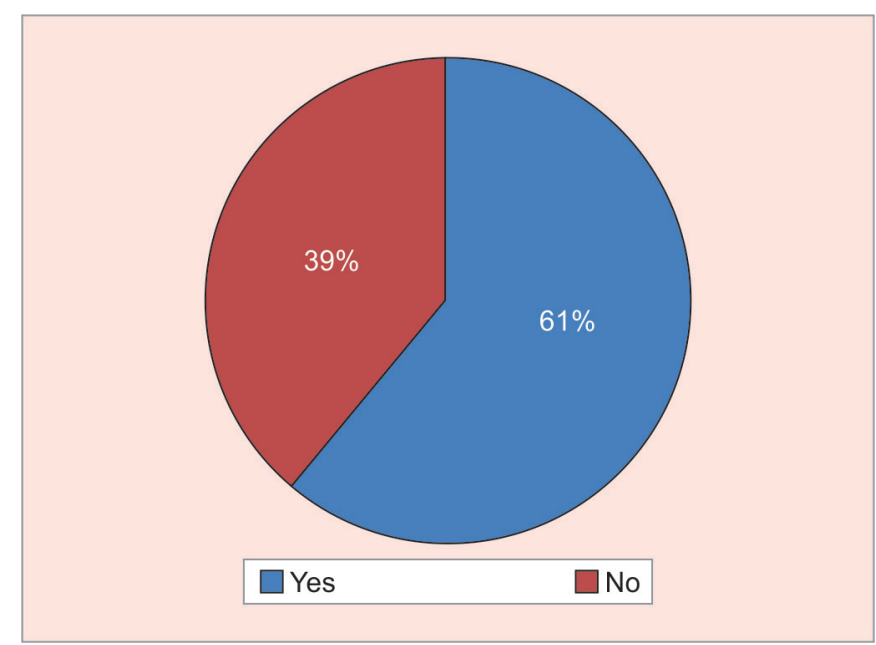

Graph 2: Distribution of fluorosis among study participants $(n=920)$ 
Table 1: Sociodemographic distribution of participants

\begin{tabular}{lll}
\hline Variable & Category & Frequency, $n$ (\%) \\
\hline Type of school of & Public & $600(65.2)$ \\
participant & Private & $320(34.8)$ \\
Age group (in years) & $10-13$ & $573(62.3)$ \\
& $14-17$ & $347(37.7)$ \\
Level of education of & Formal schooling & $885(96.3)$ \\
father & No formal schooling & $34(3.7)$ \\
Level of education of & Formal schooling & $676(73.5)$ \\
mother & No formal schooling & $244(26.5)$ \\
Type of place of & Urban & $430(46.7)$ \\
residence & Rural & $490(53.3)$ \\
\hline
\end{tabular}

Table 3: Distribution of study participants with dental caries according to the demographic characteristics $(n=920)$

\begin{tabular}{lll}
\hline $\begin{array}{l}\text { Variable } \\
\text { Category }\end{array}$ & $\begin{array}{l}\text { Yes } \\
\text { Frequency, } n(\%)\end{array}$ & $\begin{array}{l}\text { No } \\
\text { Frequency, } n \text { (\%) }\end{array}$ \\
\hline $\begin{array}{l}\text { Gender } \\
\text { Boy }\end{array}$ & $280(46.1)$ & $328(53.9)$ \\
$\begin{array}{l}\text { Girl } \\
\text { Type of school of } \\
\text { participant }\end{array}$ & $124(39.7)$ & $188(60.3)$ \\
$\begin{array}{l}\text { Public } \\
\text { Private }\end{array}$ & \\
$\begin{array}{l}\text { Age group (in years) } \\
\text { 10-13 }\end{array}$ & $248(41.3)$ & $352(58.7)$ \\
$\begin{array}{l}\text { 14-17 } \\
\text { Type of place of }\end{array}$ & $156(48.8)$ & $164(51.2)$ \\
residence & & \\
Urban & & $348(60.7)$ \\
Rural & $206(49.3)$ & $168(48.4)$ \\
\hline
\end{tabular}

schooling. Balotra block can demographically be categorized into urban and rural areas. The study population consisted of $46 \%$ urban participants and 53\% children were from rural areas (Table 1).

The study observed that the prevalence of dental caries in primary and permanent dentition was $14 \%$ and $44 \%$ respectively (Table 2). The oral health problem of dental caries was seen to be lesser in girls $(39.7 \%)$ as compared with boys $(46.1 \%)$. This could be due to the inclusion of more boys in the study as compared with girls. Dental caries were found to be more among students in government schools (58.7\%). It was also found to be more in the younger age group of 10 to 13 years $(60.7 \%)$ as compared with the older age group of 14 to 17 years $(48.4 \%)$. The oral health problem of dental caries was observed more in rural areas (59.6\%) as compared with urban areas (52.1\%; Table 3).

Dental fluorosis was approximately equal among boys (62.1\%) and girls (58.8\%). Dental fluorosis was observed in $62.1 \%$ students from government schools and in $58.9 \%$ of private schoolchildren. Close to two-thirds (65\%) of the children in the older age group (14-17 years) presented
Table 2: Distribution of caries among study participants according to the type of dentition $(n=920)$

\begin{tabular}{lll}
\hline Variable & Category & Frequency, $n$ (\%) \\
\hline Permanent dentition & Carious & $404(43.9)$ \\
& Sound & $516(56.1)$ \\
Primary dentition & Carious & $130(14.1)$ \\
& Sound & $790(85.9)$ \\
\hline
\end{tabular}

Table 4: Distribution of study participants with dental fluorosis according to the demographic characteristics $(n=920)$

\begin{tabular}{llll}
\hline \multirow{3}{*}{ Variables } & Category & $n(\%)$ & $n(\%)$ \\
\hline Gender & Boys & $226(37.9)$ & $370(62.1)$ \\
& Girls & $126(41.2)$ & $180(58.8)$ \\
Type of school of participant & Public & $223(37.9)$ & $365(62.1)$ \\
& Private & $129(41.1)$ & $185(58.9)$ \\
Age group (in years) & $10-13$ & $231(41.3)$ & $328(58.7)$ \\
& $14-17$ & $121(35.3)$ & $222(64.7)$ \\
Type of place of residence & Urban & $178(42.0)$ & $24(58.0)$ \\
& Rural & $174(36.4)$ & $304(63.6)$ \\
\hline
\end{tabular}

with dental fluorosis and an almost equal proportion $(58.7 \%)$ of younger children presented with the same. Dental fluorosis observed in children from rural areas was $63.6 \%$, slightly more as compared with urban areas (58\%; Table 4).

To account for confounding, multivariate analyses were done. Finally, presentation of dental caries was found to be associated with the type of school of participants, age group, and frequency of cleaning of teeth. Children attending private schools were 1.4 times [95\% confidence interval (CI) 1.1, 1.9; $\mathrm{p}<0.05$ ] more likely to develop dental caries as compared with children from government schools. The odds of getting caries in children between 14 and 17 years of age were 1.5 times (95\% CI, 1.1, 2.0; $p<0.05$ ) the odds of caries in children between 10 and 13 years of age. The odds of getting dental caries in children, who irregularly brush their teeth, were two times more than the odds of getting dental caries in children, who had a regular frequency of cleaning their teeth $(95 \%$ CI, 1.6,2.7; $\mathrm{p}<0.05$; Table 5).

\section{DISCUSSION}

In the last couple of years, oral health has emerged as a topic of significance in epidemiological research, with many studies being carried out all over India. Most of the studies are focused on schoolchildren since it gives them an opportunity to simultaneously do research on primary and permanent dentitions. The ill effects of caries and other health conditions are known to the community but the real hindrance comes in the implementation of the programme. The problem comes in the implementation of the program. Students of age group of 10 to 16 years were 
Development of a Communication Tool to address Oral Health Issues

\begin{tabular}{|c|c|c|c|c|}
\hline & \multirow{2}{*}{$\begin{array}{l}\text { Caries present } \\
\text { Frequency, } n(\%)\end{array}$} & \multirow{2}{*}{$\begin{array}{l}\text { Caries absent } \\
\text { Frequency, } n(\%)\end{array}$} & \multirow[b]{2}{*}{$p$-value } & \multirow[b]{2}{*}{ Odds value (Cl 95\%) } \\
\hline & & & & \\
\hline \multicolumn{5}{|c|}{ Type of school of participant } \\
\hline Public & $248(41.3)$ & $352(58.7)$ & 0.005 & 1 \\
\hline Private & $156(48.8)$ & $164(51.2)$ & & $1.4(1.1,1.9)$ \\
\hline \multicolumn{5}{|c|}{ Age group (in years) } \\
\hline $10-13$ & $225(39.3)$ & $348(60.7)$ & 0.001 & 1 \\
\hline $14-17$ & $179(51.6)$ & $168(48.4)$ & & $1.5(1.1,2.0)$ \\
\hline \multicolumn{5}{|c|}{ Frequency of cleaning teeth } \\
\hline Regular & $189(43.8)$ & $334(56.2)$ & 0.001 & 1 \\
\hline Irregular & $215(47.1)$ & $182(52.9)$ & & $2.1(1.6,2.7)$ \\
\hline
\end{tabular}

included in the study, and this is the age when permanent teeth finish erupting, and it becomes crucial to take care of teeth, as it will have a life-long effect.

With the help of a school oral-health program, we can educate children and parents together, and this will be beneficial as parents can control children's habits. For achieving the WHO goals of 2020 related to oral health, school oral health programs must be implemented consistently and regularly. The main rationale behind implementing the school oral health program is to improve a child's habit as well as parents' knowledge regarding good oral health and proper brushing technique. The parents must be aware of proper brushing techniques and fluoride knowledge, especially regarding toothpastes containing fluoride. This is a priority issue because the study shows that children used toothpastes, unaware of their fluoride content. This is a cause for concern since Balotra is a fluoride-endemic region. It was observed that the people in this region were ignorant about their oral health. They are found visiting dentists only in cases of an emergency, and no preventive step was taken during the early stages of the condition.

Prevalence of dental fluorosis, observed during the study in the Balotra block, was $61 \%$. The findings were similar to a study done in Jaipur city of Rajasthan, wherein the prevalence of dental fluorosis in children was $51 \% .^{12}$ This was also similar to results observed in Gurgaon, a fluoride-endemic area, which recorded a prevalence of $76 \%$ of dental fluorosis in children of age 12 years. ${ }^{13}$ Dental caries was found to be more in government schools (58.7\%). It was also found to be more in younger age group (10-13 years; $60.7 \%$ ) as compared with the older age group (14-17 years; $48.4 \%$ ). On the contrary, the National Oral Health Survey and fluoride mapping, where they found more prevalence of dental caries with respect to older age group. ${ }^{14,15}$

The oral health problem of dental caries was observed more in rural area (59.6\%) as compared with urban area (52.1\%). Dental fluorosis observed in children from rural areas was $63.6 \%$, slightly more as compared with urban area (58\%). The probable reason could be that the people residing in urban areas use water filters. Hence, the oral health problem of dental fluorosis was seen to be lower in children from urban areas.

Children attending private schools were 1.4 times (95\% CI, 1.1-1.9; $\mathrm{p}<0.05$ ) more likely to develop dental caries as compared with children from government schools. One of the possible reasons for this could be the higher socioeconomic status of children from private schools, thereby, giving them more access to junk food and items known to cause caries. The odds of getting caries in children between 14 and 17 years of age were 1.5 times $(95 \%$ CI 1.1, 2.0; $\mathrm{p}<0.05)$ more than the odds of getting caries in children between 10 and 13 years of age. The odds of getting dental caries in children, who irregularly brush their teeth, were 2 times more than the odds of getting dental caries in children, who had a regular frequency of cleaning their teeth $(95 \% \mathrm{CI}$, 1.6,2.7; $\mathrm{p}<0.05)$.

One of the best methods to tackle oral health diseases is increasing awareness among people, and educating as many people as possible on oral health. This will lead to a steady decline in poor oral health, mainly because people will prevent disease onset itself. The advantage of a selfadministered questionnaire over an interview is that the respondents do not feel pressurized to give socially desirable results. Since they do not have to face the interviewer and are guaranteed anonymity, the responses received are more accurate. This is particularly beneficial in case of deleterious habits.

School-going children are highly impressionable, and it is essential that they are made aware about the importance of good oral health. They are at high risk of developing deleterious habits, such as smoking, betel nut chewing, and tobacco consumption. These habits have a negative impact on children and their overall health and well-being. Hence, there is a need for awareness programs at school levels. These should focus on educating children about good oral hygiene practices, the harmful and addictive effects of betel nut and tobacco, and also the 
consequences of bad oral health. Teachers could probably be involved in this role.

\section{CONCLUSION}

Almost half of the children presented with some degree of dental caries in their permanent dentition and nearly one-fourth of the children had dental caries in their primary dentition. More than half of the children had some amount of fluorosis, ranging between very mild to severe. Prevalence of dental caries and dental fluorosis was almost equal in the urban and rural populations of Balotra block. Significant associations were found between dental caries and private schools, age group of 14 to 17 years, and irregular brushing habits. The findings of the study are indicative of lack of knowledge and awareness about oral hygiene among schoolchildren. Due to this, they are at high risk of suffering from poor oral health throughout their lives. The need of the hour is a school health program that would help change the status quo, and positively influence oral health and well-being of children.

\section{REFERENCES}

1. Gambhir RS, Gupta T. Need for oral health policy in India. Ann Med Health Sci Res 2016 Jan-Feb;6(1):50-55.

2. World Health Organization. Oral health. Geneva: WHO; [cited Jul 15]. Available from: http://www.who.int/oral_ health/disease_burden/global/en/

3. Ministry of Health and Family Welfare. Operational guidelines National Oral Health Programme (NOHP). New Delhi: Ministry of Health and Family Welfare; [cited Jul 25]. Available from: https://www.mohfw.gov.in/sites/default/ files/51318563751452762792.pdf
4. Bali RK, Mathur VB, Talwar PP, Channa HB. National oral health survey fluoride mapping 2002-2003. New Delhi: Dental Council of India; 2004. [cited $2017 \mathrm{Jul}$ 30]. Available from: http://www. dciindia.org.in/Download/Books/NOHSBOOK.pdf.

5. FDI World Dental Federation. Geneva: FDI World Dental Federation; [cited Jun 13]. Available from: http://www. fdiworldental.org/content/datamirror

6. Kothia NR, Bommireddy VS, Devaki T, Vinnakota NR, Ravoori S, Sanikommu S, Pachava S. Assessment of the status of national oral health policy in India. Int J Health Policy Manag 2015 Sep;4(9):575-581.

7. Yadav P, Kaur B, Srivastava R, Srivastava S. Oral health disparities: review. IOSR J Dent Med Sci 2014 Sep;13(9):69-72.

8. Tandon S. Challenges to the oral health workforce in India. J Dent Educ 2004 Jul;68(7 Suppl):28-33.

9. Parkash $\mathrm{H}$, Shah N. National oral health care programme: implementation strategies. Indian J Community Med 2004 Jan-Mar;29(1):3-10.

10. Sheiham A. Oral health, general health and quality of life. Bull World Health Organ 2005 Sep;83(9):644.

11. Misbahuddin MS, Fazal A, Gilani SK, Sheikh Z, Mirza AJ. The menace of betel nut and Gutka: an oral health survey of school children to assess prevalence of oral lesions in chewers versus non-chewers. Int Dent J Stud Res 2015 Dec;3(4):163-169.

12. World Health Organization. Oral health surveys: basic methods. 5th ed. Geneva: WHO; 2013. [cited May 25]. Available from: http://www.who.int/oral_health/publications/9789241548649/en

13. Gupta R, Sharma A, Gaur K, Zafer A, Manohar RK. Dental fluorosis status in school children of Jaipur (Raj) India. IOSR J Dent Med Sci 2013 Jul-Aug;8(4):51-54.

14. Mittal M, Chaudhary P, Chopra R, Khattar V. Oral health status of 5 years and 12 years old school going children in rural Gurgaon, India: an epidemiological study. J Indian Soc Pedod Prev Dent 2014 Feb;32(1):3-8.

15. Jackson SL, Vann WF Jr, Kotch JB, Pahel BT, Lee JY. Impact of poor oral health on children's school attendance and performance. Am J Public Health 2011 Oct;101(10):1900-1906. 